Article

\title{
How Can Multifunctional Agriculture Support a Transition to a Green Economy in Africa? Lessons from the COMACO Model in Zambia
}

\author{
Orleans Mfune ${ }^{1,2, *}$, Moses Ngongo Chisola ${ }^{1}$ and Ignitius Ziba ${ }^{1}$ \\ 1 Department of Geography and Environmental Studies, The University of Zambia, P. O. Box 32379, \\ Lusaka 10101, Zambia; mchisola@yahoo.com (M.N.C.); Ziba.ignitius@yahoo.com (I.Z.) \\ 2 United Nations University-Institute for Natural Resources in Africa (UNU-INRA) Green Economy Project, \\ International House, University of Ghana, Legon Campus, Accra, Ghana \\ * Correspondence: omfune@gmail.com; Tel.: +260-969-171456
}

Academic Editor: Gbadebo Oladosu

Received: 2 August 2016; Accepted: 12 September 2016; Published: 21 September 2016

\begin{abstract}
This paper examines the link between the green economy and multifunctional agriculture. In particular, the paper uses the case of the Community Markets for Conservation (COMACO) initiative, an agro-based enterprise promoting a multifunctional agriculture model in Eastern Zambia, to examine how the potential of smallholder farmers can be harnessed to support a transition towards the green economy. The empirical data on which the paper is based were collected through questionnaire surveys and in-depth interviews conducted with farmers and other actors in the agricultural sector. The results of the study show that a number of elements underpinning the COMACO model including sustainable land management practices, conservation outreach, community markets, value addition, and conservation dividends have great potential to deliver benefits related to the green economy. However, to truly foster a transition towards a green economy, a number of constraints need to be overcome. These include lack of a supportive policy and institutional framework, technological backwardness, and lack of consumer awareness of environmental information instruments such as eco-labelling.
\end{abstract}

Keywords: multifunctional agriculture; green economy; smallholder farmers; agro-based enterprise; community markets

\section{Introduction}

Growing dissatisfaction with the conventional development model driven by massive exploitation of natural capital, a huge appetite for fossil fuel and misallocation of capital is driving the search for alternative development and growth models. More recently, the notion of a green economy has gained ascendancy as the preferred alternative growth model. With the promise of delivering a low carbon, resource efficient, and socially inclusive development, the green economy has been endorsed by governments, inter-governmental organizations, businesses, and scholars alike. One of the major proponents of the green economy, the United Nations Environmental Programme (UNEP), argues that the 'green economy' should be viewed as one whose growth (in income and employment) is driven by investments (public or private) that reduce emissions and pollution, enhances energy and resource efficiency, and prevents loss of biodiversity and ecosystem services [1]. In other words, in a green economy, the generation of wealth should not result in the production of environmental risks or increase in social disparities. Indeed, the multiple crises facing the world today, such as the threats posed by climate change, loss of biodiversity, and increases in inequalities within and between regions, require that the world makes a radical departure from the status quo towards a green economy. 
Drawing from the various definitions in literature (e.g., [2-5]), a green economy is seen in this paper as being characterised by at least six key elements: (a) low carbon economic activity; (b) resource efficiency; (c) social inclusion; (d) green jobs and businesses; (e) pollution and waste reduction; and (f) protection of biodiversity and ecosystem services. Green jobs, here, are viewed as jobs in business that produce goods or provide services beneficial to the environment and conserve natural resources (and includes workers with green skills) [3,6]. As Yi [4] notes, green jobs are multipurpose, providing tax and revenue in addition to employment.

Inevitably, with its focus on change, the green economy has important implications for various sectors that underpin the global economic system. Among these sectors is agriculture. As a source of livelihood for millions of people across the developing world, agriculture is key to sustainability and green economy aspirations. For decades, a model of agriculture based on intensive production systems to support high yielding crops has been promoted in a bid to feed the world's growing population. Over the years, a lot of studies have already drawn our attention to the ecological implications of extensive use of agro-chemicals and tillage practices in such agricultural systems [7-9]. Use of agro-chemicals and tillage practices have resulted in negative impacts on natural ecosystems and biodiversity and increased greenhouse gas emissions [10-12]. As Pearce et al. [13] note, unchecked abuse of resources (such as fertilizers) in an agricultural system do not only affect the sustainability of agroecosystems but also increase its vulnerability to external shocks and stresses such as market conditions, prolonged dry seasons, and changes in land tenure and others.

While, as already noted, on one hand, agriculture has been associated with an array of environmental externalities, on the other; there is a growing argument that agriculture provides one of the greatest opportunities for change towards a green economy. According to Musvoto et al. [2] agricultural activities potentially offer solutions to a myriad of social, economic, and environmental challenges. However, for agriculture to drive the green economy, it is acknowledged that changes are required within the sector [2]. As Leakey [14] equally argues, agriculture needs to be rethought, to move it from being an environmental culprit to an environmental, social, and economic savior. Here, multifunctional agriculture emerges as one such strategy that is reconfiguring agriculture towards some of the elements associated with a green economy. Traditionally, agricultural spaces have been viewed as primarily production spaces rather than multifunctional spaces [15]. In this regard, agro-based businesses have often ignored other functions that can be provided by agricultural landscapes. The concept of multifunctional agriculture, in this regard, highlights the fact that agriculture can play a significant role in delivering a range of socio-economic and environmental dividends beyond its productive functions [15]. In other words, this is a type of agriculture that embraces various other functions besides food production $[8,11,16,17]$. As a concept, the term multifunctional agriculture was first used at the Earth Summit in Rio de Janeiro (1992) [18] and further developed by the IAASTD [19] who have been highly instrumental in promoting its principles and practices.

Today, it is evident that there is a growing trend across the world towards multifunctional agricultural systems such as eco-agriculture and conservation agriculture that not only focus on food production but also ecosystem services and biodiversity conservation $[7,20,21]$. To its proponents, multifunctional agriculture is key to halting deforestation, biodiversity loss, land degradation, loss of ecosystem services in rural environments, and addressing inequalities in society $[7,8,17,20]$. However, it is important to note here that analyses of multifunctional agriculture have mostly focused on examining the role of agriculture in delivering ecosystem services and addressing environmental externalities in agricultural systems.

While provision of ecosystem services and addressing environmental externalities is a critical element in multifunctional agriculture, the notion of a green economy suggests that much more is required of agriculture. Beyond, addressing environmental externalities, the economic and social dimensions of the green economy requires that agriculture also addresses the inequalities that characterize the sector such as unequal access to farming inputs and markets. A few initiatives in Africa are already showing the importance of going beyond the focus on environmental externalities 
in delivering multifunctional agriculture. One such notable multifunctional agricultural initiative has been the agroforestry based three-step model implemented in Cameroon [22-25]. According to the proponents [22-25], the three step model involves rehabilitation of degraded lands through planting leguminous trees and shrubs as the first step. The second step involves the domestication of indigenous trees to produce salable products and in the third step; products are processed to add value and then marketed. Studies on these initiatives are already generating important lessons about the value of multifunctional agriculture and demonstrating the need to study such initiatives more keenly, especially in the context of the green economy. Moreover, with the concept of the green economy being new, the reality on the ground is that currently, there is insufficient information to aid green economy strategies or policy development [2] especially in African countries such as Zambia. In this regard, there are still some gaps in our understanding of the type of strategies and conditions that offer the most effective approach for supporting agriculture systems that are resilient, provide sustainable livelihoods, and at the same time foster inclusive and sustained economic growth and environmental sustainability.

Given these circumstances, in this paper, we draw on both empirical and theoretical data to analyze a model on the ground that similarly holds promise for fostering a green economy through multifunctional agriculture. In particular, we examine a multifunctional agricultural model being promoted in the Eastern Zambia by an organization called Community Markets for Conservation (COMACO). COMACO runs an agro-based enterprise that seeks to green the agricultural sector through promotion of sustainable land management practices, community markets, and premium pricing. The goal of the COMACO model is to simultaneously improve farmers' production and protect the environment. While being similar than the three-step model, the COMACO is conservation farming based and includes elements of eco-labeling and conservation dividends. By examining this model, we seek to answer one important question: how can multifunctional agriculture in Zambia be used to harness the potential of smallholder farmers to support a transition towards a green economy?

In the COMACO model, the multifunctional agriculture approach adopted is that of conservation farming (often used synonymously with the term conservation agriculture). Conservation farming $(\mathrm{CF})$ is a farming approach that emphasizes zero or minimum tillage, use of permanent planting basins, retention of crop residues on the farm, reduction in inorganic fertilizer use and promotion of animal manure use. Further, conservation farming also encourages integration of nitro-fixing shrubs and other woody plants in crop lands, crop rotation, and mixed cropping. For an extended discussion of the major characteristics of conservation farming, see [11,26].

\section{Materials and Methods}

Our study is premised on the idea that to support a green economy, multifunctional agriculture must not only be underpinned by the motivation to produce food and fibers, but must also be guided by social, economic, and environmental goals. In this regard, our analysis follows a four step approach. In the first step we examine the conventional agricultural model in the study area that provides, to some extent, a basis for comparison with the COMACO model. In the next step, we then examine the COMACO model in terms of how its multifunctional agricultural strategy is translated into practice. This then, allows us, in the third stage, to tease out the most innovative features of the COMACO model that hold promise for a green economy. We thus, with the fourth step, generate lessons from the model on how smallholder farmer's potential can be harnessed to foster a transition towards the green economy.

Empirical studies on which this data is based were carried out in eastern Zambia, in Chikwa and Kambombo Chiefdoms of the Chama District. The study area is part of the Luangwa Valley Ecosystem where COMACO has been operating. COMACO has been promoting conservation farming as a sustainable farming practice. The farmers are recruited on a voluntary basis and have to pledge to undertake conservation measures on their farm plots as the only condition for joining the COMACO initiative. It is important to note, here, that although there are other organizations promoting conservation farming, the COMACO model was selected for this study because of its 
unique approach to multifunctional agriculture. Perhaps, the most distinctive features of the model, especially in the context of a green economy, is the linking of conservation farmers to community markets, its focus on value addition, and the use of premium prices to compensate farmers who undertake environmental measures on their farms and avoid deforestation and encroachment into wildlife areas. The products from CF are sold under a label called 'It's Wild'. These features represent an important departure from initiatives solely focused on sustainable land management practices.

The Work of COMACO is concentrated along the Luangwa Valley Ecosystem, home to the South Luangwa and North Luangwa National Parks, two of Zambia's top wildlife parks. The valley is rich in both aquatic and terrestrial biodiversity. In addition to its rich flora, the ecosystem is home to a variety of large fauna such as lions, wild dogs, elephants, water bucks, and Thornicroft's Giraffes which are endemic to the area. The areas where COMACO is operating are presented in Figure 1.

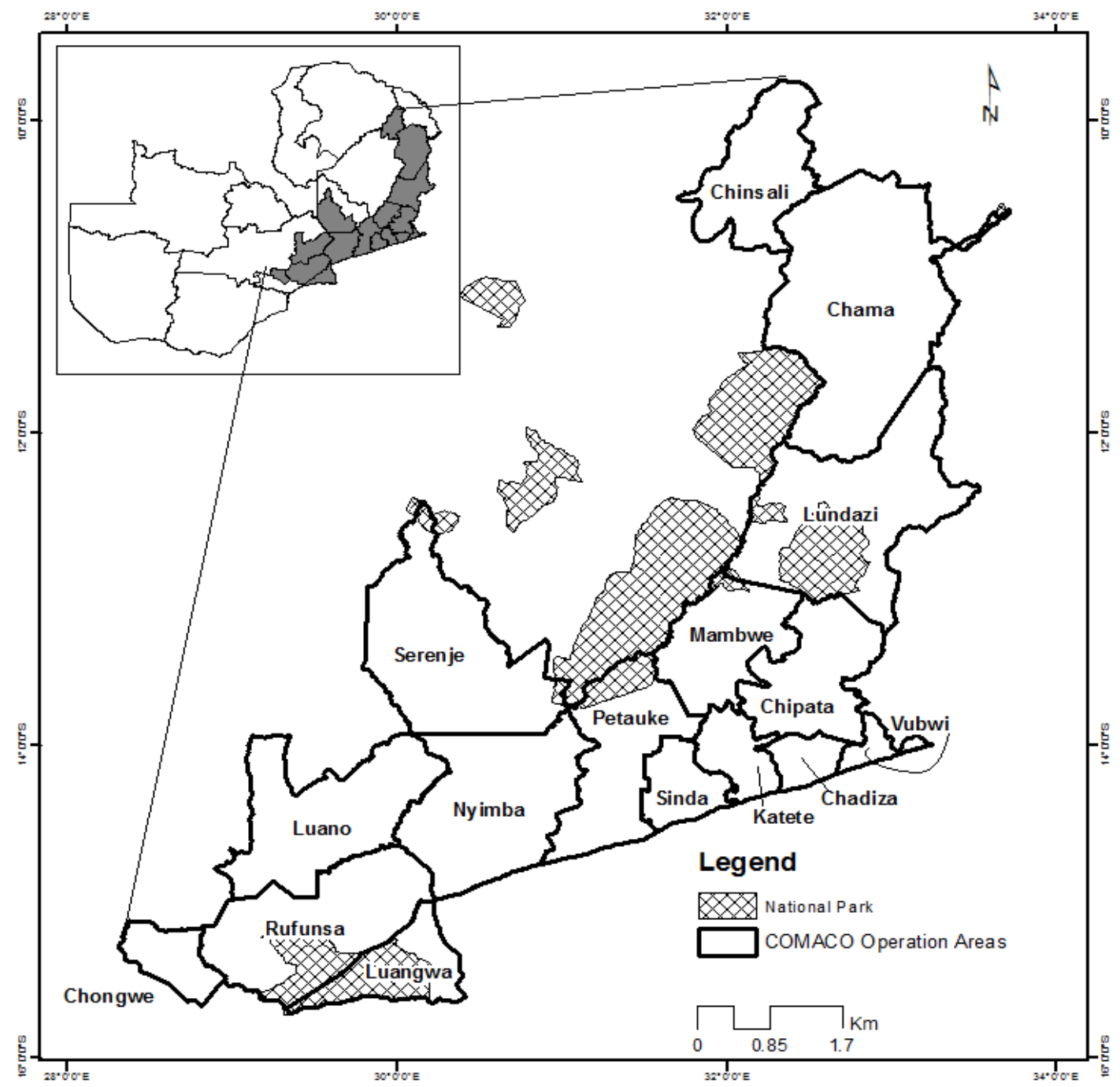

Figure 1. COMACO areas of operation.

Although the Luangwa Valley area is an ecosystem of outstanding biodiversity, it is also home to among the poorest people in the country. According to Seshaman [27], Chama, the study district, was in 2000 among the poorest 16 (16) in Zambia with incidences of poverty averaging $74.5 \%$. At that time, the county had 72 districts. Mainly, the people in the area depend on rain-fed agriculture for their livelihood. Figure 2 presents Chama as the study area. 


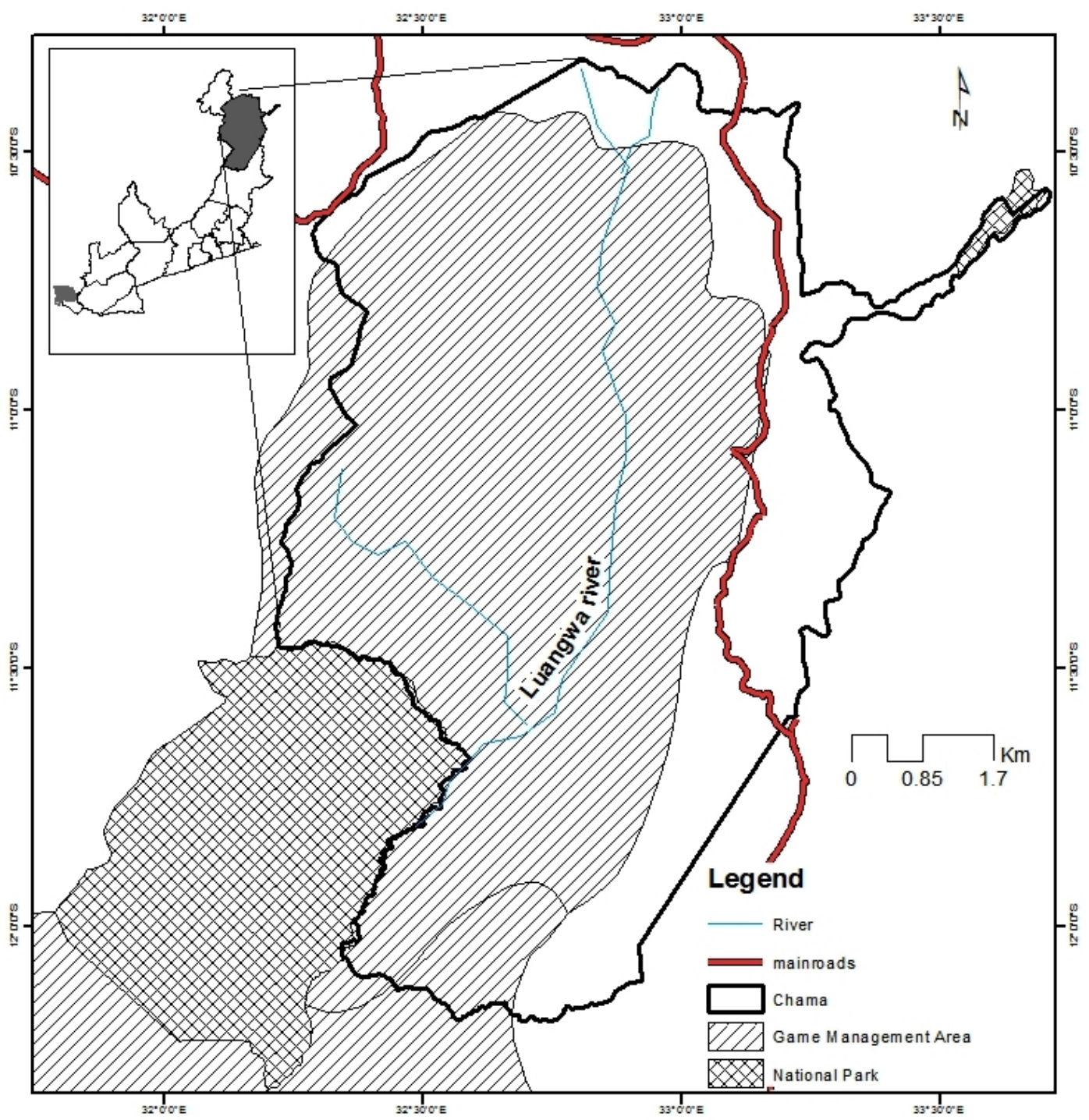

Figure 2. Chama district.

In Chama, data for local level studies was collected using a questionnaire survey. In total, 206 questionnaires were administered to households in the study area. Half (50\%) of these households are farmers participating in the COMACO model. Theses households were selected from COMACO records kept at COMACO depots and identified in the community with the help of COMACO lead farmers. From the records, there are nearly 20,000 farmers that are participating in the COMACO program in the study area. However, for this study, participants were randomly selected from a population of 8000 farming households that were within an estimated $20 \mathrm{Km}$ radius of COMACO depots in the area. This study was delimited to this area because of accessibility constraints beyond the $20 \mathrm{Km}$ radius. For each, of the respondents involved in the COMACO program, the nearest non-COMACO neighbor was also targeted for the survey. This was done to allow for comparison of findings between households participating in the COMACO model and those not participating.

The questionnaire was used to collect data on farm size, type of crops cultivated, on-farm practices, and benefits or demerits of conservation farming as viewed by community members. This data also allowed the study to test (using Chi-square test with Yates correction) whether there were any significant statistical differences in farming practices between COMACO farmers and non-COMACO farmers. Besides, the questionnaire survey, 20 in-depth interviews were also conducted with key informants associated with the COMACO model and agriculture in general. Interviews were conducted 
with agricultural officers, wildlife officers, COMACO representatives, lead farmers, and other local community members.

The questionnaire survey and interviews conducted in Chama were complimented by a consumer survey. As the processed products emanating from the programs are sold in the major supermarkets across the country, a consumer survey was conducted with shoppers outside the premises of three major supermarkets. These are Shoprite, PickNPay, and Spar. These supermarkets were selected on the basis that they are the three main supermarkets which also stock COMACO products. In total, 40 consumers participated in the survey. The shoppers who participated in the study constituted those who were willing to respond to questions or fill in the survey form. In the consumer survey, respondents were asked questions relating to their awareness of COMACO products, eco-labelling, and willingness to pay premium prices for environmentally friendly products.

\section{Results and Discussion}

\subsection{Agricultural Livelihoods in Chama District}

Chama District, where this study was carried out, is largely rural with a very small urban center. The majority of the population is highly reliant on crop-based agriculture. In Kambombo and Chikwa Chiefdoms, for example, crop farming represented the most important economic activity with $98 \%$ of the research participants identifying it as their main source of livelihood. Other important sources of livelihoods include livestock rearing (mainly small ruminants and poultry) and small scale trading. Crop farming is mainly dominated by maize which is grown both for subsistence and for sale. Nearly all farmers that participated in the survey indicated that they grew maize in addition to other crops such as cotton, rice, ground-nuts, millet, and sorghum. From these results, it is evident that agriculture occupies a very important place in the economy of the district, with maize being the top crop. This mostly stems from the fact that maize is the staple crop in the area.

The agricultural sector is mainly dominated by smallholder farmers. Among the study respondents, the study found that the mean size of land cultivated by farmers is two hectares. Only a few farmers (less than 6\%) cultivate land sizes in excess of four hectares. Clearly, the agricultural sector in the area is characterized by an absence of large-scale commercial farmers. In Zambia, this is not unique to Chama. Large-scale farming mostly occurs along the line of rail regions that have easy access to transportation lines, the market, and other services. Chama on the other, like many other rural districts is not connected by rail, has a poor road connection and is far from major market centers. Indeed, among some of the factors that farmers who participated in this study identified as major agricultural hurdles include difficulties of accessing markets of agricultural produce.

\subsection{Features of Conventional Farming in Chama}

Like other areas of Zambia, conventional farming involving conventional tillage and application of external or inorganic inputs dominates the crop-based agricultural sector in the study area. In this approach, land preparation involves clearing the farm plot of wild vegetation, crop residues (often burnt), and creation of seedbeds. The crops grown, mainly maize, are sustained by application of inorganic fertilizers. In the study, $60 \%$ of the farmers who practice conventional farming and participated in this study, indicated that they used fertilizer (mainly nitrogen and phosphorous fertilizer) to support growth of crops. Considering the difficulties that smallholder farmer's face in accessing inorganic fertilizers, this represents a slightly higher level of fertilizer use when compared to the national level. At the national level, statistics show that $55 \%$ of smallholder farmers use inorganic fertilizer [28]. Unfortunately, this use of fertilizer does not often translate into higher crop yields among smallholder farmers because of delays in fertilizer application (sometimes due to late access to it), misapplication, and insufficient use [28].

Besides use of inorganic fertilizer, the farming approach is characterized by agricultural extensification in which farmers periodically expand their agricultural activities into virgin lands 
mostly to replace fertilizer starved lands. As will be seen in the subsequent sections, over $70 \%$ of the farmers who participated in the study indicated that they extended their farm plots in the past five years, mostly into virgin territory. For conservationists that were interviewed in this study, this level of agricultural extension is of particular concern as virgin lands often include protected forest areas or wildlife areas.

This trend where farmers have been extending their fields into virgin territory is not new and should be viewed in its historical context. Prior to the 1990s, agriculture in the country was largely sustained by fertilizer subsidies through the socialist policies of the then government. In the 1990s, the socialist policies in Zambia gave way to a free market economy. This saw the withdrawal of many agriculture related subsidies. It is argued that the withdrawal of state intervention in agriculture significantly affected crop and livestock production and created food deficits in rural areas. In turn, this increased the pressure on natural resources and biodiversity as households turned to non-farm products for survival, while others begun to expand into virgin land into protected areas in a bid to acquire fertile virgin lands to replace fertilizer starved soils [29-31]. In addition, the loss of Jobs through privatization and public sector reforms triggered an urban-to rural migration which added further pressure on forested and wildlife lands as some of these migrants began to settle on protected lands. Indeed, some studies report an increase in encroachment of protected areas during this period as shrinking urban employment opportunities forced many to take on farming [30-33]. According to Mbindo [31], forest cover in Zambia, which was at 39,755,000 hectares in 1999, had reduced to $31,346,000$ hectares by 2000 while in national parks, poaching was rife as people sought to complement their agricultural livelihood.

It is this type of farming that has mainly been linked to an array of environmental impacts which includes biodiversity loss, poor soil organic matter, disturbance of soil structure through tillage, pollution of aquatic systems from runoff of nitrates, and land-use based GHG emissions. The features of this agriculture are shown in Figure 3.
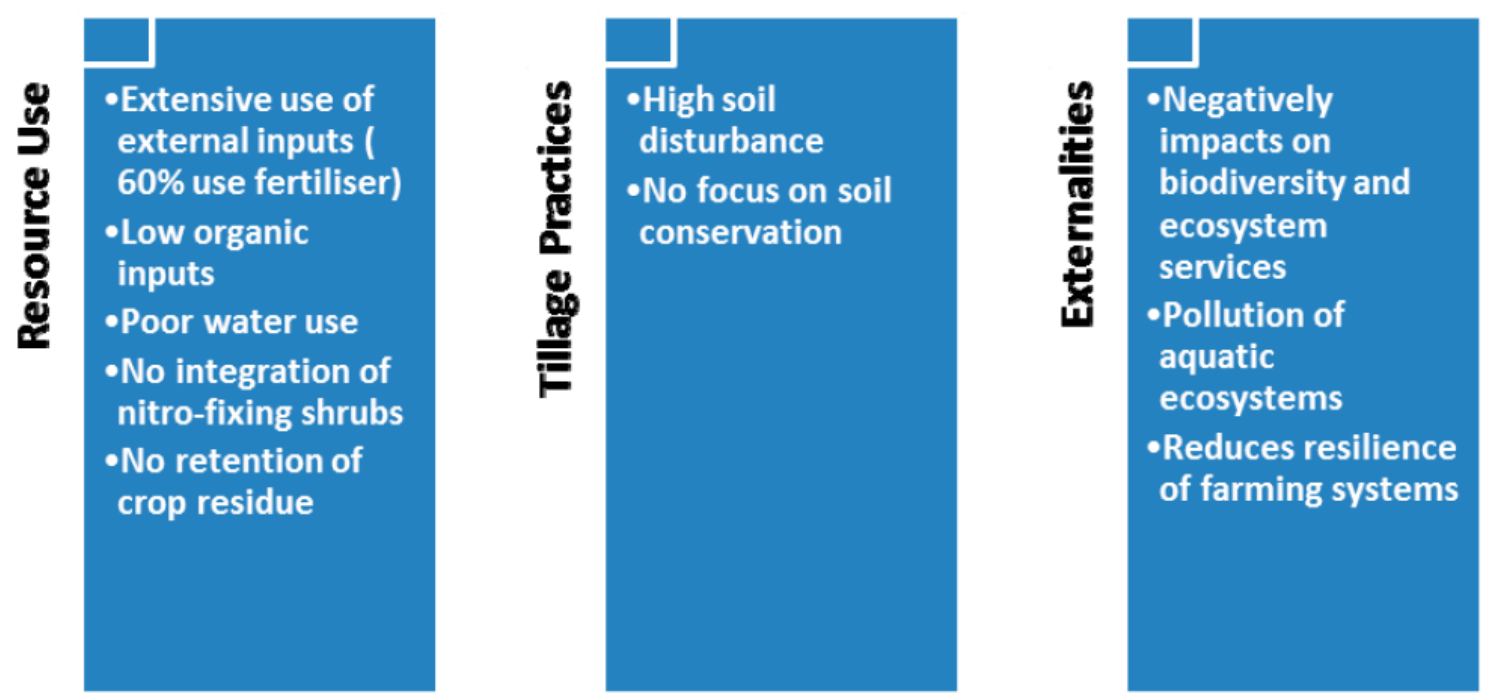

Figure 3. Features of conventional farming in the study area.

From the results of the study and the discussion above, it is evident that this type of agriculture is primarily aimed at production of food and fibers which does not include environmental goals. In this model, there is little space for green economy aspirations such as green products, jobs, or businesses. From a sustainability point of view, this is an example of agriculture that can be considered as unsustainable in the long run. To change this picture and move towards a green economy trajectory requires decoupling crop production from environmental damage and excessive resource use. This, it appears, is what the COMACO model seeks to achieve. 


\subsection{COMACO's Multifunctional Agricultural Model}

As already noted in the preceding section of this work, at the heart of the COMACO model is the use of conservation farming as a sustainable land management strategy. Farmers who embrace conservation farming are expected to adopt a range of sustainable farming practices that include minimum tillage, crop residue retention, and use of permanent planting basins. Ideally, if farmers religiously followed these practices, it is expected that this would lead to high yields, less or no use of external inputs, increased on-farm water conservation, improved soil nutrients, less erosion and have positive effects on on-farm carbon sequestration and storage. From the results of the study, the level of adoption of sustainable farming practices is much higher among COMACO farmers than non-COMACO farmers. For example, all COMACO (100\%) respondents were found to practice minimum tillage while only $2.9 \%$ of non-COMACO farmers had adopted the practice. Further, COMACO farmers showed higher levels of adoption of other practices such as retention of crop residues on farm plot after harvest, use of animal manure, crop rotation, and intercropping. For these, the Chi-square test results showed that the differences between COMACO farmers and non-COMACO farmers were significant. Table 1 indicates the level of adoption of sustainable farming practices between COMACO farmers and non-COMACO farmers.

Table 1. Differences in Level of Adoption of Sustainable Farming Practices.

\begin{tabular}{|c|c|c|}
\hline Farm Practices & COMACO Farmers $(\%)(n=103)$ & Non-COMACO Farmers $(\%)(n=103)$ \\
\hline Minimum Tillage ${ }^{* * *}$ & 100.0 & 2.9 \\
\hline Mixed Cropping & 65.0 & 53.4 \\
\hline Crop residue Retention ${ }^{* * *}$ & 60.2 & 17.5 \\
\hline Manure Use ${ }^{* *}$ & 38.8 & 21.4 \\
\hline Integration of Shrubs *** & 31.1 & 1.9 \\
\hline Fertilizer Use ${ }^{* *}$ & 36.9 & 60.2 \\
\hline Crop Rotation ** & 82.5 & 61.2 \\
\hline Intercropping * & 36.9 & 19.4 \\
\hline Mulching & 29.1 & 22.3 \\
\hline
\end{tabular}

While the level of adoption of sustainable farming practices is much higher among COMACO farmers, it is important to note that not all practices promoted by COMACO were adopted by COMACO farmers. As can be seen from Table 1, apart from minimum tillage, there is no single practice that was adopted by $100 \%$ of COMACO farmers who are practicing conservation farming. Further, it is evident that there are some practices that are less adopted than others. For example, while less than $50 \%$ of the respondents' practice intercropping, mulching, and integrate nitro-fixing shrubs in their crop fields, some elements such as crop rotation, mixed cropping, and crop-residue retention are practiced by the majority of the conservation farmers. Moreover, the study found that some practices such as mixed farming were already widespread in the study area before the introduction of conservation farming. In this regard, the study found no significant differences $\left(X^{2}=3.372, n=206\right.$, $p=0.663$ ) in levels of adoption of mixed cropping between COMACO and non-COMACO farmers. It appears, here, that COMACO is building on some of the existing indigenous farming practices in the area.

Of critical importance here is the fact that among COMACO farmers, fertilizer use is significantly lower than non-COMACO farmers who are involved in conventional farming. This difference was also found to be significant $\left(X^{2}=10.28, n=206, p=0.003\right)$. Only $36.9 \%$ of the conservation farmers indicated that they used fertilizer on their farm plot (cf $60.2 \%$ for conventional farming). This reflects a considerable reduction in use of inorganic fertilizers among conservation farmers.

Perhaps, another major observation in this study is that, apart from selective adoption of some of the conservation farming practices, very few farmers place their entire cultivated land 
under conservation farming. Figure 4 shows the proportion of land that farmers reserve for conservation farming.

\section{Proportion of land under Conservation Farming (CF)}
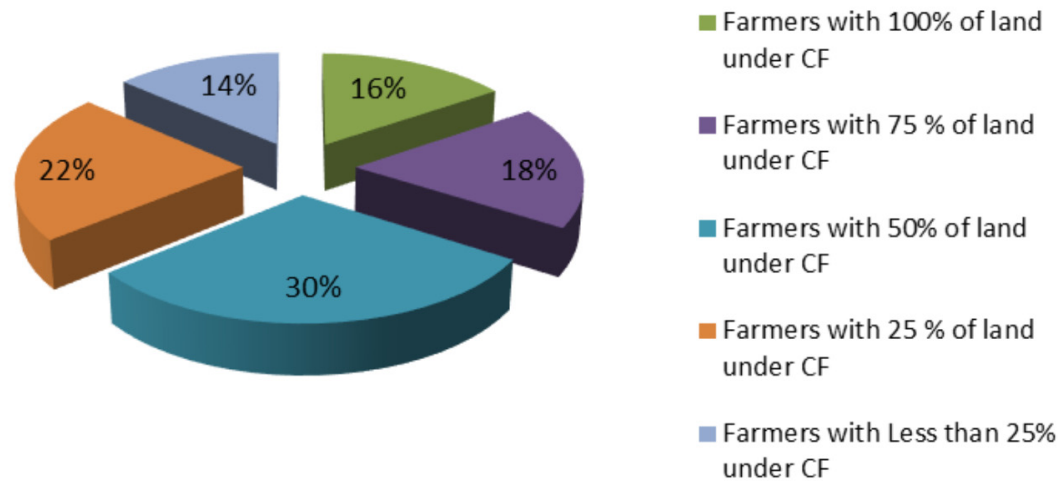

Figure 4. Proportion of land that is placed under conservation farming.

As can be seen from Figure 4, only a small proportion of farmers who participated in the study $(16 \%)$ have placed their entire cultivated land under conservation farming (CF). For the majority farmers only part of their cultivated land is under CF. This, in reality, means that nearly $85 \%$ of COMACO farmers also practice conventional farming. While farmers do point to important benefits associated with $\mathrm{CF}$, including improved crop yields, it is clear that there are important bottlenecks to complete adoption of CF. Among the bottlenecks to full adoption identified by the farmers include too much labor involved in the creation of planting basins, weeds, and lack of advanced technology such as rippers to ease the pressure on family labor. During interviews with some of the key informants, it was found that these factors are among the most important constraints to adoption of conservation farming. Indeed, some of the respondents that still practice conventional farming noted that they were not involved in conservation because it was too labor intensive.

Still, despite the selective adoption of conservation farming practices, the results also show that farmers are highly appreciative of some of the elements of conservation farming. Some of the benefits that farmers identified are presented in Figure 5.

As can been seen, over half (67\%) of the respondents that participated in the household survey single out 'good yields' as one of the most important benefits they have gained from conservation farming practices. Indeed, in a more extended study than this one, Nshimbi and Vinya [34] claim that they found that more than $80 \%$ of COMACO farmers directly attributed increased crop production on their farm plots to conservation farming promoted by COMACO. Besides good yields, Figure 5 also shows that another most important benefit that farmers identified was that their farming systems were becoming more resilient to water stresses most often associated with climatic changes. This is largely the result of use of permanent planting basins which allow for on-farm water conservation and therefore buffer against water stresses induced by prolonged dry spells. In this regard, conservation farming emerges as a climate adaptation technology. 


\section{Most Appreciated Benefits of Conservation Farming}

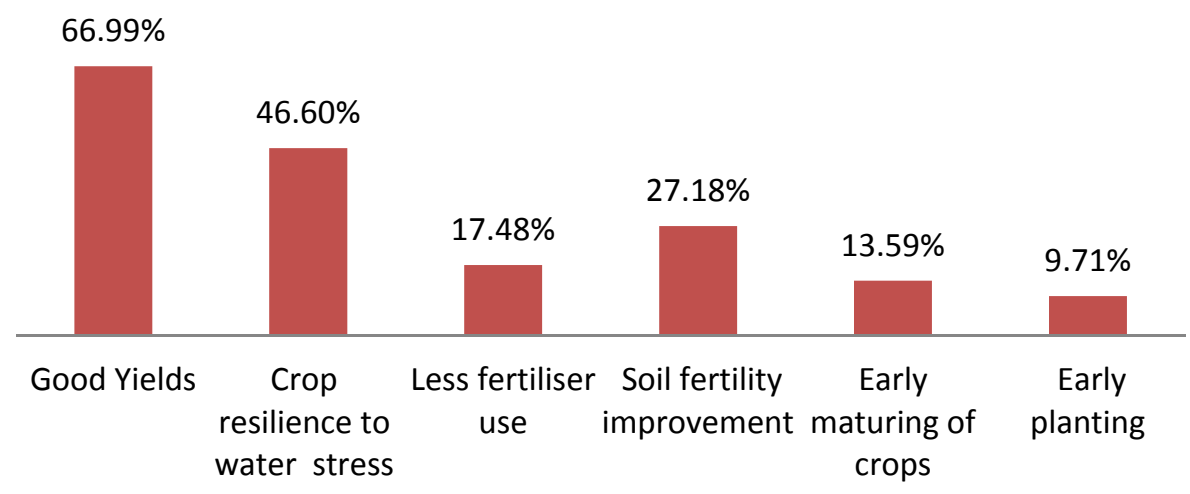

Figure 5. Most Appreciated Benefits of Conservation Farming by COMACO farmers.

\subsection{Conservation Farming Practice and the Environment}

As earlier noted, CF as promoted by COMACO seeks to not only improve agricultural productivity but also deliver environmental dividends beyond the farm-site, including halting of deforestation. While representatives of COMACO who participated in the study claim that so far, COMACO has been successful in doing so, evidence on the ground is rather mixed. Certainly as seen in Table 1, there are a number of elements where COMACO's claims can be substantiated. At a micro-level (i.e., farm site level), COMACO has been successful in fostering a reduction in fertilizer use and increase in uptake of a number of sustainable farming practices such as crop rotation, intercropping, and on-farm crop residue retention. All these have potentially beneficial effects on the environment.

There is also a huge claim that because of COMACO efforts, wildlife in the Luangwa Valley Area has increased considerably. However, in this study, we were unable to empirically verify this claim because of two things. First, because we lack objectively collected baseline data and secondly, we were unable to do so without isolating the initiatives of other actors involved in wildlife protection in the area. In this regard, a better picture of how the model has performed in halting wildlife depletion is best provided by Lewis [35] who makes explicit links between the COMACO initiative and wildlife conservation. Further, other studies elsewhere also note that such type of sustainable agricultural approaches can be achieved in harmony with wildlife. On the other hand, our study found that the COMACO approach has been, to some extent, unable to halt agricultural extensification. Our micro-level data show that farmers, including those under CF, continue to expand their farm plots into virgin lands (Table 2). Indeed, the study did not find any significant differences between COMACO and Non-COMACO farmers $\left(\mathrm{X}^{2}=1.58, p=0.207\right)$ in terms of expansion of farm plots. In both groups, more than half of the respondents (68\% of COMACO farmers and $80 \%$ of non-COMACO farmers) have expanded their fields over the past five years (Table 2). Of all who extended their farm plots, more than $70 \%$ did so by opening new plots on 'virgin' (or new) land (Figure 6).

Table 2. Differences in Agricultural Extensification.

\begin{tabular}{ccccc}
\hline & \multicolumn{2}{c}{ COMACO Farmers } & \multicolumn{2}{c}{ Non-COMACO Farmers } \\
\cline { 2 - 4 } & & $\%$ & $\%$ \\
\hline Extended Farm Over the Past Five Years & 71 & 68.9 & 80 & 77.7 \\
Did Not Extend Farm Over the Past Five Years & 32 & 31.1 & 23 & 22.3 \\
Total & 103 & 100 & 103 & 100 \\
\hline
\end{tabular}

Chi-square test, 1 degree of freedom (df): not significant at $p=0.207$. Source: Authors, 2016. 


\title{
Proportion of Farmers Who Extended Farm Plot into
} Virgin Land

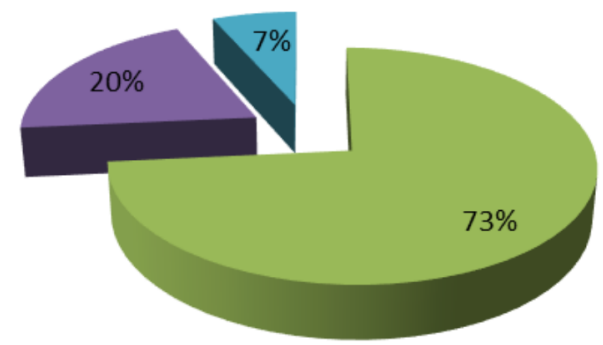

\author{
- Virgin land \\ - Fallow Land \\ - Both Virgin and Fallow
}

Figure 6. Proportion of Farmers Who Extended Farm Plots to Virgin Land.

Partly, the inability of the COMACO model to halt expansion of farm plots to virgin land arises from the fact that $\mathrm{CF}$ is only partially adopted by farmers in the area.

\subsection{Innovative Features of the COMACO Model}

Notwithstanding the limitations and constraints to conservation farming emerging from the results of the study, the COMACO model still represents an important attempt at greening the agricultural sector through sustainable land management practices. Here, conservation agriculture is used as a multifunctional agricultural strategy. As earlier noted, while COMACO is not the only actor promoting conservation agriculture in Zambia; the COMACO approach is quite unique from other similar attempts. This is because in promoting conservation agriculture, most actors are mainly concerned with increasing crop yields, efficiency in agro-resource use and buffering crop based agriculture against climate related risks. In this regard, conservation agriculture still remains single-sector centered (i.e., focusing on the agricultural sector alone). Further, the promotion of $\mathrm{CF}$ mostly focuses on the production side and is delinked from other components of the agricultural value chain such as value addition and marketing.

As a departure from other approaches to conservation farming, the COMACO model assumes a truly multifunctional character with potential to deliver social, economic, and ecological benefits. In the model, conservation farming is conceptualized as an approach for not only improving agricultural productivity and resource use efficiency, but also for fostering biodiversity conservation and halting the expansion of agriculture into forests and wildlife habitats. In this regard, in the model, on-farm practices are accompanied by conservation outreach programs. In this way, the COMACO approach deliberately attempts to bridge the gap between agriculture and conservation. This is important, as traditionally, agriculture and biodiversity conservation have been viewed as two separate domains of policy and practice $[9,20]$. Thus, we envision here, that if a rural green economy is ever to be a reality, agricultural production, and biodiversity conservation need not be considered as incompatible goals. Many studies dealing with agri-environmental management now prove that agriculture spaces can be important arenas of biodiversity conservation and ecosystem services management $[14,16]$. These studies render support for shift in conservation, to go beyond protected areas to encompass various types of socio-ecological systems, including agricultural environments, where lands can be used for multiple purposes (see also [20,36]. It is here, where agricultural businesses can make the greatest impacts by integrating biodiversity and ecosystem services protection in their activities. Figure 7 shows the multi-functionality of conservation farming as promoted by the COMACO model. 

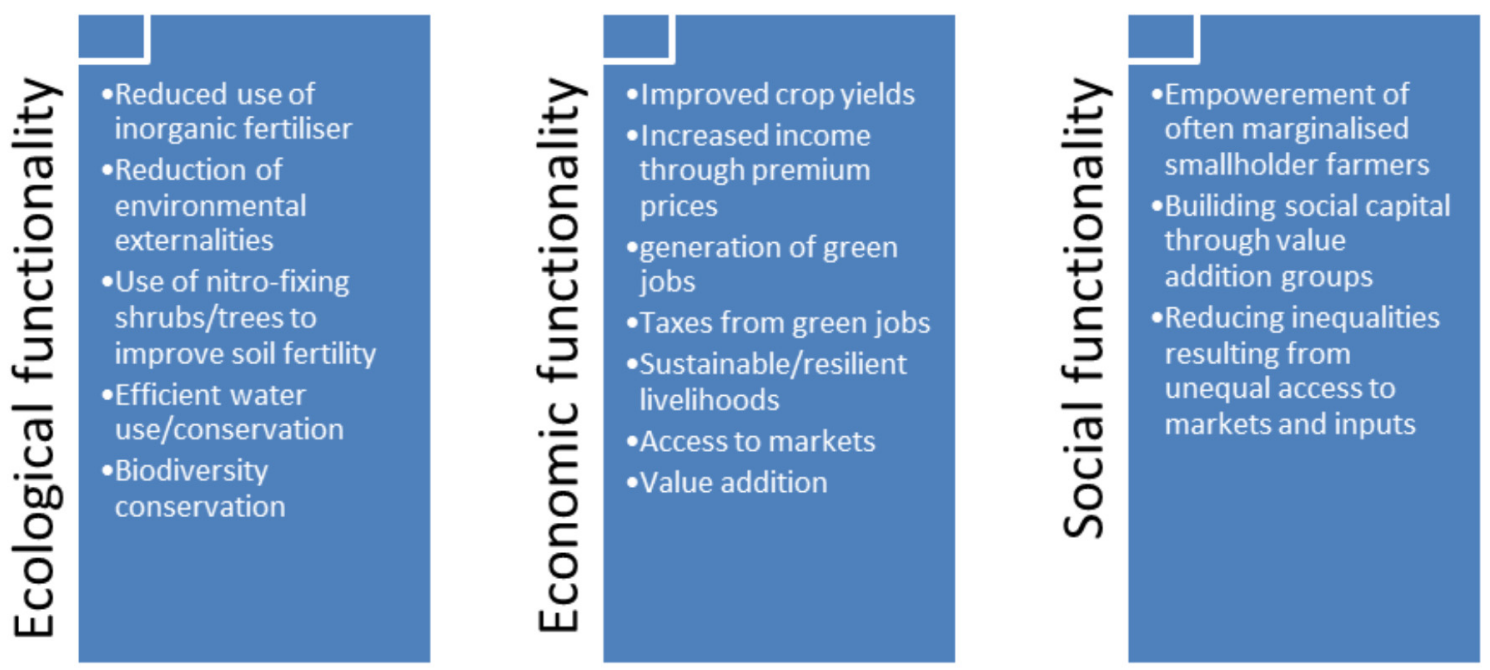

Figure 7. Multifunctionality of the COMACO agricultural model.

Beyond the farm site, COMACO is involved in provision of markets for farmers' produce. Through what are termed as community markets, COMACO provide ready markets for farmers' produce, cutting distances to markets and allowing for quick payments for their produce. Indeed, in this study, the results show that quick payments for produce, and easy access to and reduced distance to the market are among the elements of the COMACO model most appreciated by farmers. Figure 8 presents some of the benefits of the COMACO model that farmers in the study identified beyond simply sustainable land management practices.

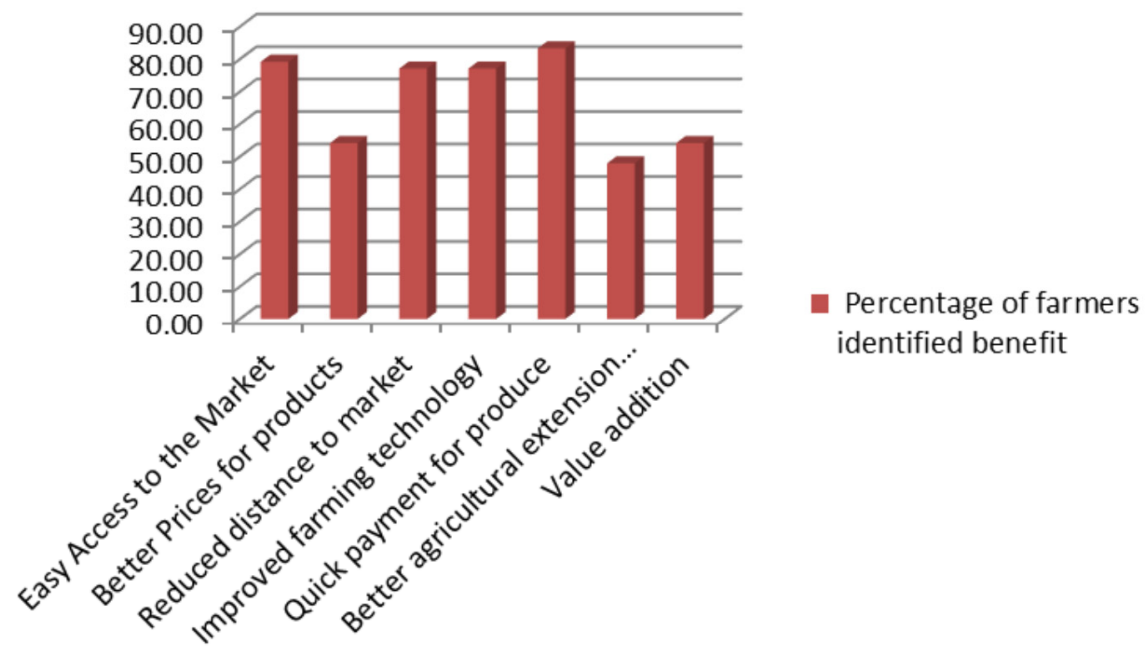

Figure 8. Perceived benefits of the COMACO model.

Further, there is also an attempt to draw on new environmental voluntary instruments such as premium pricing and eco-labelling in order to incentivize conservation actions by farmers. In this regard, to compensate for undertaking environmental measures on their farm plots, products from conservation farming attract what has been termed as 'conservation dividends'. According to a COMACO officer that participated in this study, a premium price is offered to these farmers which are $20 \%$ more than the standard crop prices offered on conventional markets. During interviews, it was noted by some of the respondents in the study that the use of premium prices has made it more profitable for farmers to engage in sustainable agricultural practices than poaching or charcoal production. 
Within the program, farmers are organized into groups which engage into value addition. The processed products are then packaged and marketed in Zambia's urban markets (as eco-friendly products) under the label 'It's Wild'. 'It's Wild' is a label that draws attention to the fact that the products are organically produced and aimed at supporting conservation efforts. In a way, the brand mirrors an eco-label which conveys environmental information to the consumer. From the results of this study, there is no doubt that COMACO has scored some level of success in marketing the label 'It's Wild'. Today, 'It's Wild' products can be found in major supermarkets in Zambian cities including Lusaka. For example, Shoprite and PickNPay, two of the leading supermarkets all stock these products. Similarly, our consumer survey shows a high level awareness of the existence of these products. In particular, the study shows that consumers are mostly aware of 'It's Wild Chama Rice', peanut butter and honey products. Thirty six (36), representing $90 \%$ of the 40 consumers who participated in the survey had indicated that they had purchased at least one of these products before.

However, an important concern here is that most consumers did not associate the 'It's Wild' products with environmental concerns. In fact, more than half of the respondents noted that they purchased the products because they liked the taste of the products and only $12 \%$ indicated that they were motivated by environmental concerns. This situation, however, shows a lack of awareness among consumers of the importance of environmental information on products they purchase. Indeed, when consumers were asked if they had any knowledge of eco-labels, more than $90 \%$ of them expressed ignorance of what they were all about. However, when asked if they were willing to pay a little bit more for a product that was produced in an environmentally friendly manner than a similar product that was not, more than $72 \%$ responded 'yes'. Thus, it seems here, that some consumers do have environmental concerns in regard to how a product is produced but are largely unaware that labelling conveys such information.

The lack of awareness of environmental information tools such as eco-labelling and premium pricing also stems from the fact that, at the national level, there have been no deliberate policy and institutional efforts to popularize these instruments, be it in agriculture or other sectors. Moreover, the environmental sector is also characterized by an absence of independent certification schemes. These factors, in addition to constraints affecting the adoption of conservation farming such as the pressure on family labor and lack of appropriate ripping technology are among the hurdles that need to be overcome in order to allow multifunctional agriculture support a transition towards a green economy. It must be recognized that an important pursuit such as the green economy cannot be achieved on the basis of mere rhetoric. Going forward, the country will need to develop green economy policy frameworks that take these factors into cognition. As yet, other than policies supportive of sustainable land management strategies, there are none explicitly focusing on the green economy.

\subsection{Lessons From the COMACO model}

From the discussion of the COMACO model in the preceding sections of this paper, it is evident that the COMACO model holds great potential for integrating agri-business with biodiversity and ecosystem services concerns. As a rural-based agricultural enterprise operating in some of the poorest (yet biologically rich areas of Zambia), the model has potential to revolutionize the agriculture industry in the country because of its unique focus on sustainable land practices, value addition, and provision of missing infrastructure such as missing markets and hence lowering farmers transaction costs

There are a number of policy lessons that can be drawn from the COMACO model, and are of critical importance to harnessing the potential of smallholder farmers to support the transition towards a green economy. First, as already noted, among the factors that condition success in African agriculture is the issue of access to and use of fertilizers among smallholder farmers ([10]). It is noteworthy, here, that the COMACO model demonstrates the need for minimization of costly inputs in smallholder farming systems in order to reduce farmers' costs, improve resource use, and competitiveness of their produce. Moreover, the model draws our attention to the need to give priority to fostering use of organic fertilizers and other biological means of improving smallholder farming systems. This may 
have the duo effect of reducing externalities associated with inorganic fertilizer use while also reducing farmer's costs of production. It is important to note here, that besides conservation farming, organic agriculture, which overly emphasizes use of biological means of enhancing soil fertility, is another strategy that can easily play an important role in supporting the greening of agriculture in Zambia.

The potential for organic agriculture in the country is great. Zambia has thousands of farmers already engaged in organic agriculture and was in 2008, ranked as fourth on countries with the highest number of organic farms in Africa [37]. In this paper's view, if supported by a favorable policy environment, both conservation farming and organic agriculture would play an important role in wide-scale development of green businesses and jobs through certification schemes, marketing and sales of products. Already, the COMACO model demonstrates that green businesses and jobs can be created within the rural economy. Value addition, agriculture extension services and development of new markets such as community markets all make it possible for new businesses and jobs to emerge. It is important in this regard, that policy makers give explicit attention to these elements in their quest to promote the greening of the agricultural sector.

Second, the COMACO model also raises the need to buttress smallholder agricultural systems against climate change related stresses and shocks if they are to play a role in the transition towards a green economy. The results demonstrate that undertaking climate change risk reduction strategies need not be very costly as simple measures such as use of permanent planting basins (which promote on-farm water conservation) can equally be effective. It is crucial, however, that in promoting such measures, COMACO, government departments, and organizations promoting sustainable agricultural practices pay particular attention to the demand that such practices place on family labor, a concern raised by most respondents in this study.

The concern with labor brings us to the third point: It is our contention here that a green economy cannot be achieved on the back of technological backwardness of smallholder farmers. As already noted, the results of the study show that while farmers in the COMACO model appreciate a number of elements of multifunctional agriculture, lack of appropriate and less labor intensive technology remains a hindrance to advancing sustainable land use practices among smallholder farmers. Here the COMACO model can take a leaf from the three step model to include a focus on design and fabrication of technology both for tillage, processing, and value addition. In Chama, farmers lack ripping technology and rely on handheld tools to create planting basins and clear weeds on conservation farms. Consequently, farmers only put a fraction of their fields under conservation farming. In fact, this finding is not unique to Chama. In another study on conservation farming practices in Central Zambia, we found that farmers rarely place their entire fields under conservation farming, largely due to family labor constraints and lack of ripping technology [15]. In this regard, it seems that to harness the potential of smallholder farmers towards a green economy, the role of appropriate agricultural technology that meets farmers' expectations is crucial. Thus, green agricultural policies and strategies must also seek to increase farmers' access to appropriate ripping technology.

Far beyond what happens at the level of the farm plot, the COMACO model also demonstrates that to harness the potential of smallholders, access to markets, and premium pricing are of crucial importance to fostering their productivity and incentivizing their participation in multifunctional agriculture. Often, as the case of Chama shows, smallholders located in rural areas have to contend with long distances to markets and unfavorable prices for their produce. Creating appropriate farmer-centered markets such as community markets allows agriculture to deal with these elements and contribute to resolving the perennial problem of unequal access to high paying markets.

\section{Conclusions}

With the emergence of the concept of the green economy, the need for agro-initiatives to integrate biodiversity, ecosystem services, and socio-economic goals in agricultural practices has been brought to the fore. However, as business actors, environmentalists, and academics are only getting to grasp the essential elements of a green economy; few practical and successful examples of initiatives that 
are pursuing these strategies in African countries such as Zambia exist. The COMACO model, in this regard, represents one of the few rural based agri-business models in Zambia that seem to have embraced some of the elements of a green economy. Elsewhere in Africa, similar models that hold great promise include the three step model implemented by the World Agroforestry Centre in Cameroon. Many of the elements in the COMACO model, including a focus on sustainable land management practices, emphasis on conservation, value addition, and local markets for farmer products, represent an important departure from conventional farming that is often solely focused on production of food and fibers. However, COMACO can also benefit from the three step model especially with regard to domestication of indigenous trees and shrubs and skills development in processing and design of value addition equipment and technology.

While it is clear that smallholder agriculture in Zambia is constrained by a variety of factors that include poor productivity, lack of access to inputs, missing markets, and a variety of environmental ills (such as climate change and poor soils), this paper shows that COMACO seem to have turned these constraints into a green agri-business opportunity. By looking at some of the innovative features of the COMACO model, the paper shows that opportunities for harnessing the potential of smallholder farmers towards the green economy not only lie in sustainable land management practices, but also in developing new, accessible markets for farmer products, innovative incentives (such as conservation dividends and premium prices) and value addition. However, lessons from the same model also show that a number of constraints need to be overcome for multifunctional agriculture initiatives to thrive. These include lack of a supportive policy and institutional framework, technological backwardness of the smallholder farmers, and lack of consumer awareness of environmental information instruments.

Acknowledgments: We thank the United Nations University-Institute for Natural Resources in Africa (UNU-INRA) for their technical and financial support towards the research project that led to the production of this paper. In particular, we thank Calvin Atewamba and anonymous reviewers whose comments were invaluable in improving the quality of the paper. We also thank our Research Assistants in the Chama District who travelled long distances to administer the survey instruments.

Author Contributions: Orleans Mfune, Moses Ngongo Chisola, and Ignitius Ziba conceived and designed the experiments; Orleans Mfune, Moses Ngongo Chisola, and Ignitius Ziba performed the experiments; Orleans Mfune, Moses Ngongo Chisola, and Ignitius Ziba analyzed the data; Orleans Mfune contributed materials/analysis tools; Orleans Mfune, Moses Ngongo Chisola, and Ignitius Ziba wrote the paper.

Conflicts of Interest: This work has been submitted as a working paper to UNU-INRA who also the funded the research project that led to the production of the paper. In this regard, permission to publish the working paper as a research article has been obtained from UNU-INRA.

\section{References}

1. United Nations Environment Programme (UNEP). Towards a Green Economy: Pathways to Sustainable Development: A synthesis for Policy Makers; UNEP: Nairobi, Kenya, 2011.

2. Musvoto, C.; Nahman, A.; Nortje, C.; de Wet, B.; Mahumani, B. Agriculture and the Green Economy in South Africa; Council for Scientific and Industrial Research (CSIR): Pretoria, South Africa, 2014.

3. Connolly, K.; Allan, G.J.; Mclintyre, S.G. The Evolution of Green Jobs in Scotland: A Hybrid Approach. Energy Policy 2016, 88, 355-360. [CrossRef]

4. Yi, H. Green Businesses in a Clean Energy Economy: Analysing Drivers of Business Growth in US States. Energy 2014, 68, 922-929. [CrossRef]

5. Cai, W.; Wang, C.; Chen, J.; Wang, S. Green Economy and Green Jobs: Myth or Reality? The Case of China's Power Generation Sector. Energy 2011, 36, 5995-6003.

6. Furchtgott-Roth, D. The Elusive and Expensive Green Growth. Energy Econ. 2012, 34, 543-552. [CrossRef]

7. Mattison, H.A.; Norris, K. Bridging the Gap between Agricultural Policy, Land Use and Biodiversity. Trends Ecol. Evol. 2005, 20, 610-616. [CrossRef] [PubMed]

8. Milestad, R.; Ahstrom, J.; Bjorklund, J. Essential Multiple Functions of Farms in Rural Communities and Landscapes. Renew. Agric. Food Systems. 2011, 26, 137-148. [CrossRef]

9. Batary, P.; Bald, A.; Kleijn, D.; Tscharntke, T. Landscape-moderated Biodiversity Effects of Agri-environmental Management. Proc. Royal Soc. 2011, 278, 1894-1902. [CrossRef] [PubMed] 
10. United Nations Environment Programme (UNEP). Agriculture and the Green Economy. 2015. Available online: http:/ / www.unep.ch/etb/publications / Agriculture/flyer\%20UNEP\%20FOAM.pdf (accessed on 29 December 2015).

11. Dumanski, J.; Peiretti, R.; Benets, J.; McGarry, D.; Pieri, C. The Paradigm of Conservation Agriculture. Proceedings of the World Association of Soil and Water Conservation, August, 2006; P1:58-64. Available online: http://www.unapcaem.org/publication/ConservationAgri/ParaOfCA.pdf (accessed on 31 January 2016).

12. Cunder, T. The Role of Rural Development Policy in Environmental and Land Management in Slovenia. J. Cent. Eur. Agric. 2007, 8, 237-242.

13. Pearce, D.; Markandya, A.; Barbier, E. Blue Print for a Green Economy; Earthscan Publications Ltd.: London, UK, 1989.

14. Leakey, R.R.R. Living with the Trees of Life: Towards the Transformation of Tropical Agriculture; Centre for Agriculture and Bioscience International (CABI): Wallingford, UK, 2012; p. 224.

15. Gorman, M.; Mannion, J.; Kinsella, J.; Bogue, P. Connecting Environmental Management and Farm Households Livelihoods: The Rural Environment Protection Scheme in Ireland. J. Environ. Policy Plan. 2001, 3, 137-147. [CrossRef]

16. Mfune, O. Extending Conservation to Farmlands in Zambia. Prescribed Practices and Reality. J. Sustain. Dev. 2014, 7, 46-59.

17. Jean-Vasile, A. Multi-functional Agriculture and the Green Economy. In Sustainable Practices: Concepts, Methodologies, Tools, and Applications; Information Science Reference: Hershey, PA, USA, 2013; pp. 1701-1722.

18. United Nations Conference on Environment and Development (UNCED). Agenda 21-An Action Plan for the Next Century; United Nations Conference on Environment and Development: New York, NY, USA, 1992.

19. McIntyre, B.D.; Herren, H.; Wakhungu, J.; Watson, R. (Eds.) International Assessment of Agricultural Knowledge Science and Technology for Development: Global Report; Island Press: New York, NY, USA, 2008.

20. Scherr, S.J.; McNeely, J.A. Biodiversity Conservation and agricultural sustainability: Towards a new conservation paradigm of eco-agriculture landscapes. Philos. Trans. Royal Soc. 2008, 363, 477-494. [CrossRef] [PubMed]

21. Kareiva, P.; Watts, S.; McDonald, R.; Boucher, T. Domesticated Nature: Shaping Landscapes and Ecosystems for Human Welfare. Science 2007, 316, 1866-1869. [CrossRef] [PubMed]

22. Leakey, R.R.B. Agroforestry: A delivery mechanism for multi-functional agriculture. In Handbook of Agroforestry: Management Practices and Environmental Impact; Kellimore, R.L., Ed.; Nova: New York, NY, USA, 2010; pp. 461-471.

23. Asaah, E.K.; Tchoundjeu, Z.; Leakey, R.R.B.; Takousting, B.; Njong, J.; Edang, I. Trees, agroforestry and multifunctional agriculture in Cameroon. Int. J. Agric. Sustain. 2011, 9, 110-119. [CrossRef]

24. Leakey, R.R.B. Agroforestry-Participatory domestication of trees. In Encyclopedia of Agriculture and Food Systems; van Alfen, N.K., Ed.; Elsevier Publishers: San Diego, CA, USA, 2014; Volume 1, pp. 253-269.

25. Leaky, R.R.B. The Role of Trees in Agroecology and Sustainable Agriculture in the Tropics. Annu. Rev. Phytopathol. 2014, 52, 113-133. [CrossRef] [PubMed]

26. Baudron, F.; Mwanza, H.; Triomphe, B.; Bwalya, M. Conservation Agriculture in Zambia: A Case Study of Southern Province; FAO/ACT: Nairobi, Kenya, 2007.

27. Seshaman, V. Deprivation in Zambia: District-Level Profiles and Rankings Based on an Index of Depravation; United Nations International Children's Emergency Fund (UNICEF): Lusaka, Zambia, 2000.

28. Tembo, S.; Sitko, N. Technical Compendium: Descriptive Agricultural Statistics and Analysis for Zambia; IAPRA Working Paper 76; Indaba Agricultural Policy Research Institute: Lusaka, Zambia, 2013.

29. Kajoba, G.M.; Chidumayo, E.N. Degradation of Forest Reserves in Zambia: A Case Study of Muyama in Central Zambia. UNEP Desertification Control Bull. 1999, 35, 59-66.

30. Kajoba, M.G. Squatting in Protected Forest Areas: A Dilemma for Sustainable Natural Resources Management; Research Report; Provincial Forest Action Programme and Forest Department: Ndola, Zambia, 1999.

31. Mbindo, K. Forest Cover Crisis in the Tropics: A Case Study of Zambia. In Proceedings of the XII World Forestry Congress, Quebec, QC, Canada, 21-28 September 2003.

32. Chidumayo, E. Land-cover Transformation in Central Zambia: Role of Agriculture, Biomass Energy and Rural Livelihoods. In Proceedings of the International Symposium on 'Area Studies: Past Experiences and Future Visions', Kyoto, Japan, 19-22 January 2001. 
33. GRZ-MTNR. Zambia Forest Action Plan. Challenges and Opportunities; GRZ: Lusaka, Zambia, 1988.

34. Nshimbi, M.; Vinya, R. Impacts of Public-Private Partnerships on Local Livelihood and Natural Re-sources Dynamics: Perceptions from Eastern Zambia. Resources 2014, 3, 471-485. [CrossRef]

35. Lewis, D. Community Markets for Conservation (COMACO) links Biodiversity Conservation with Sustainable Improvements in Livelihoods and Food Production. PNAS 2011, 108, 13957-13962. [CrossRef] [PubMed]

36. Mery, G.; Alfro, R.; Kanninen, M.; Lobovikov, M. (Eds.) Forests in the Global Balance-Changing Conservation Paradigms; International Union of Forest Research Organisations: Vienna, Austria, 2005.

37. International Federation of Organic Agriculture Movements (IFOAM). One Earth, Many Hands: IFOAM 2008 Annual Report; IFOAM: Bonn, Germany, 2008.

(C) 2016 by the authors; licensee MDPI, Basel, Switzerland. This article is an open access article distributed under the terms and conditions of the Creative Commons Attribution (CC-BY) license (http:/ / creativecommons.org/licenses/by/4.0/). 